\title{
Article
}

\section{Structure-properties relationships in alkaline treated rice husk reinforced thermoplastic cassava starch biocomposites}

Boonsuk, Phetdaphat, Sukolrat, Apinya, Bourkaew, Sain, Kaewtatip, Kaewta, Chantarak, Sirinya, Kelarakis, Antonios and Chaibundit, Chiraphon

Available at http://clok.uclan.ac.uk/35984/

Boonsuk, Phetdaphat, Sukolrat, Apinya, Bourkaew, Sain, Kaewtatip, Kaewta, Chantarak, Sirinya, Kelarakis, Antonios ORCID: 0000-0002-8112-5176 and Chaibundit, Chiraphon (2021) Structure-properties relationships in alkaline treated rice husk reinforced thermoplastic cassava starch biocomposites. International Journal of Biological Macromolecules, 167 . pp. 130-140. ISSN $0141-8130$

It is advisable to refer to the publisher's version if you intend to cite from the work. http://dx.doi.org/10.1016/j.ijbiomac.2020.11.157

For more information about UCLan's research in this area go to http://www.uclan.ac.uk/researchgroups/ and search for <name of research Group>.

For information about Research generally at UCLan please go to http://www.uclan.ac.uk/research/

All outputs in CLoK are protected by Intellectual Property Rights law, including Copyright law. Copyright, IPR and Moral Rights for the works on this site are retained by the individual authors and/or other copyright owners. Terms and conditions for use of this material are defined in the policies page. 
Structure-properties relationships in alkaline treated rice husk reinforced thermoplastic cassava starch biocomposites

Phetdaphat Boonsuk, ${ }^{1}$ Apinya Sukolrat, ${ }^{2}$ Sian Bourkaew, ${ }^{1}$ Kaewta Kaewtatip, ${ }^{1}$ Sirinya Chantarak, ${ }^{1}$ Antonios Kelarakis, ${ }^{3}$ Chiraphon Chaibundit ${ }^{1, *}$

${ }^{1}$ Division of Physical Science, Faculty of Science, Prince of Songkla University, Hat Yai, Songkhla, Thailand, 90110.

${ }^{2}$ Office of Scientific Instrument and Testing, Prince of Songkla University, Hat Yai, Songkhla, Thailand, 90110.

${ }^{3}$ UCLan Research Centre for Smart Materials, School of Natural Sciences, University of Central Lancashire, Preston PR1 2HE, UK.

* Corresponding author:

E-mail address: chiraphon.c@psu.ac.th

Telephone: +66 74288364 


\begin{abstract}
The study focuses on structure-properties relationships in thermoplastic cassava starch (TPS) based biocomposites comprising 5-20 wt $\%$ of untreated and treated rice husk (RH). Alkaline treatment with $11 \% \mathrm{w} / \mathrm{v} \mathrm{NaOH}$ removed the hemicellulose layer of $\mathrm{RH}$ as confirmed by Fourier-transform infrared spectroscopy (FTIR) and thermogravimetric analysis (TGA), and resulted in a larger population of $-\mathrm{OH}$ groups exposing on the fibril surface. Consequently, the filler-matrix interactions between treated RH and TPS were enhanced, although Brunauer-Emmett-Teller surface area analysis indicated that the surface area of treated RH was not increased. Interestingly, the biocomposites contained $20 \mathrm{wt} \%$ treated $\mathrm{RH}$ showed substantially improved tensile strength by a factor of $220 \%$ compared to the neat TPS. The biocomposite at $15 \mathrm{wt} \%$ treated RH showed high water absorption. TPS with all treated RH contents showed high biodegradation rate, while the thermal stability of the TPS/treated RH biocomposites was slightly decreased. These novel composites showed promising properties for applications as absorbents.
\end{abstract}

Keywords: thermoplastic cassava starch; surface treated; biodegradable 


\section{Introduction}

An increasing number of countries have introduced regulations and laws of banning disposable plastics [1]. To that end, particular emphasis is given to natural fiber-reinforced degradable matrices, such as poly(lactic acid), poly(butylene succinate), polyhydroxybutyrate, and thermoplastic starch [2]. A range of starch-based biodegradable polymer composites have been investigated including okra-cellulosic fiber/corn starch [3], kenaf/starch [4], laver/starch [5], untreated bagasse/cassava starch [6], treated bagasse/cassava starch [7], luffa/cassava starch [8], cellulose fiber derived from newspaper/corn starch [9], wood fiber/potato starch [10], and almond shell/starch-based polymer composites [11].

Starch is a completely biodegradable polysaccharide and one of the most abundant renewable resources. It is a crystalline material consisting of linear amylose and highly branched amylopectin [12]. Thermoplastic starch absorbs water readily and has poor thermal and mechanical properties compared to synthetic polymers. However, plasticizers such as glycerol and additives such as luffa fibers [8] and rubber wood sawdust [13] were reported to improve its tensile strength, thermal stability, and water resistance.

Natural fibers are of particular interest due to their low density, biodegradability, reduced production of ash during incineration, and good adhesion of fiber-polar polymer matrix, such as starches and proteins. The most abundant natural fibers are cellulose (a semicrystalline polysaccharide), lignin (a polymer composed of propyl phenol units) and hemicellulose (a cementing substance between cellulose and lignin). Cellulose and hemicellulose are hydrophilic, while lignin is relatively hydrophobic [14]. Plant fibers are typically derived from leaf (e.g. sisal), bast (e.g. flax, jute, and hemp), grass and reed fibers (e.g. rice husk), core fibers (e.g. hemp, jute, and kenaf), and seed fibers (e.g. cotton and coir) $[1]$. 
Natural fibers are promising reinforcement agents for polymer composites, due to their low production cost, energy-efficient nature and environmental friendliness [15]. A promising strategy to overcome their rather poor mechanical properties relies on the introduction of surface-treated fiber by means of by alkaline, silane, peroxide [15], acid, and ultraviolet-ozonolysis treatment [16]. Alkaline treatment is the most frequently applied method that leads to increased surface roughness and, thereby, improved mechanical properties of fibers [15].

Rice husk $(\mathrm{RH})$ is a byproduct from rice processing and separated from the grain during the milling process. The main components of RH are cellulose (25-35\%), hemicellulose (18-21\%), lignin (26-31\%), silica (15-17\%), solubles (2-5\%), and moisture (ca. 7.5\%) [17-20]. Silica $\left(\mathrm{SiO}_{2}\right)$ is intrinsic to the outer layer of $\mathrm{RH}$ [21]. The use of $\mathrm{RH}$ as a reinforcement in biocomposites is increasing rapidly [16]. Alkaline is the most common surface treatment of $\mathrm{RH}[22]$. Alkaline treatment using sodium hydroxide $(\mathrm{NaOH})$ depolymerized the cellulose component of RH, exposing short length crystallites. Alkaline treatment removed certain amounts of lignin, wax, and oils from the outer surface of cell walls of RH fiber [23]. A number of reports explored the use of alkaline treated fiber. For example, Ndazi et al. modified RH with $2-8 \% \mathrm{w} / \mathrm{v} \mathrm{NaOH}$ solution at $25^{\circ} \mathrm{C}$ for $24 \mathrm{~h}$ then used it to reinforce phenol formaldehyde resin [24]. The removal of carbonyl groups and $\mathrm{SiO}_{2}$, observed by Fourier transform infrared spectrometer in attenuated total reflectance mode (ATR-FTIR), improved the interfacial bonding between RH and resin, hence the modulus of elasticity increased. Kaewtatip and Thongmee studied the TPS/treated bagasse fiber composites [7]. The bagasse fiber was treated by low alkaline concentration $(1 \mathrm{wt} \% \mathrm{NaOH})$. The rough surfaces of treated bagasse caused the strong adhesion between the fiber and TPS matrix observed by scanning electron microscopy (SEM). The addition of treated bagasse fiber decreased the water absorption of the composites. Royan et al. prepared $2 \% \mathrm{w} / \mathrm{v} \mathrm{NaOH}$ 
treated RH reinforced high density polyethylene (HDPE) [16]. Surface treated RH was rough and improved the adhesion with HDPE matrix. Tong et al. studied the effect of high alkaline concentration $(10 \mathrm{wt} \% \mathrm{NaOH})$ on bamboo fiber, the morphology and physico-chemical properties on treated fibers [36]. The treated and untreated fibers were characterized by FTIR, thermogravimetric analysis (TGA), and SEM. The mechanical properties of a single fiber were determined. Tensile strength and modulus of the alkali-treated fiber were improved by $45.6 \%$ and $72 \%$, respectively, compared to the untreated fiber. The roughness of treated surface fiber was reduced after the alkaline treatment. However, in that work, the treated fiber was not further used to prepare polymer composites.

The high potential fiber modification was made by in-situ biological fiber modification during the TPS/wood fiber composite processing [10]. Incorporation of modified wood fiber up to $41.5 \mathrm{wt} \%$ in potato starch composites was prepared by a mechanical mixing and subsequently by a thermocompression. Wood fiber was simultaneously modified during the processing by the deep eutectic solvents (DES), i.e. choline chloride with urea or glycerol and imidazole with glycerol. DES played three important roles in the composites: i.e. plasticizing effect, modification of fiber surfaces, and improving the interfacial adhesion between fiber and starch. The mechanical, thermomechanical, moisture sorption, and surface wetting properties of the composites were dependent on DES type. The TPS/wood fiber/glycerol/imidazole composites exhibited the tensile strength up to $11 \mathrm{MPa}$, Young's modulus to $590 \mathrm{MPa}$, moisture sorption to $4 \mathrm{wt} \%$, and water contact angle about $100^{\circ}$. The recent work of TPS/almond shell fiber was reported by García et al. [11]. The composite containing $30 \mathrm{wt} \%$ almond shell and starch (Mater-Bi DI01A) was prepared. The different varieties of almond shell on the properties of the composites were studied. Tensile, flexural, Charpy impact, hardness tests, and thermal properties by differential scanning calorimetry (DSC) and TGA of the composites were 
determined. The results showed that the different types of almond shell had no difference on the properties of the composites.

In this study, a systematic investigation on the effect of ground $\mathrm{RH}$ both untreated and high concentration of $\mathrm{NaOH}$-treated, on a series of physico-chemical properties of cassava starch-based biocomposites is reported. The paper is organized in two parts. In the first part, the structural characterization of untreated $\mathrm{RH}$ and treated $\mathrm{RH}$ fillers is reported. In the second part, the structure and the properties of the thermoplastic cassava starch/RH biocomposites is reported. In particular, emphasis is given on the evaluation of their thermal and mechanical properties, water absorption, and biodegradation. The effect of particle size of untreated RH on the biocomposites was also studied. To our knowledge, such a systematic study is absent from the literature.

\section{Experimental}

\subsection{Materials}

Cassava starch was purchased from a local market (Red Cat Brand, Kriangkrai Company, Ltd.). Rice husk (RH) was obtained from a local rice mill. Glycerol (SigmaAldrich, Steinheim, Germany) and sodium hydroxide $(\mathrm{NaOH})$ pellets (Lobachemie) were used as received.

\subsection{Preparation of ground rice husk and alkaline treated rice husk}

RH was thoroughly washed with water to remove dust and other impurities and dried in an oven at $80^{\circ} \mathrm{C}$ for $24 \mathrm{~h}$. The washed and dried $\mathrm{RH}$ was ground in a grinding machine (Fritsh, motor grinder pulverisette 2, Industriestraße 8 6580. Idar-Oberstein W. Germany) at $75 \mathrm{rpm}$ for $2 \mathrm{~h}$. The ground $\mathrm{RH}$ was collected as samples of three sizes and labeled $R H 1$, $R H 2$, and $R H 3$ (Figure 1). RH was first sieved through a 33 mesh to remove the biggest particles, which were discarded. The remaining $\mathrm{RH}$ was labeled $R H 1$. A part of $R H 1$ was then 
sieved through a 100 mesh to separate the smallest particles, which were labeled $R H 2$. The remaining $\mathrm{RH}$ that did not pass through the 100 mesh was labeled $R H 3$. Only $R H 1$ was treated with alkaline solution. To do so, $40 \mathrm{~g}$ of $R H 1$ was soaked in $180 \mathrm{~mL}$ of $11 \% \mathrm{w} / \mathrm{v}$ $\mathrm{NaOH}$ for $24 \mathrm{~h}$ at room temperature $\left(T=29 \pm 1^{\circ} \mathrm{C}\right)$, followed by repeated washing with distilled water until neutral $\mathrm{pH}$ readings. The obtained alkaline treated $\mathrm{RH}$ was dried at $80^{\circ} \mathrm{C}$ for another $24 \mathrm{~h}$ and at $60^{\circ} \mathrm{C}$ for $24 \mathrm{~h}$ and was labeled treated $R H 1$. All samples were kept in a desiccator at $21 \%$ relative humidity prior to use. The length of 100 particles for each $\mathrm{RH}$ was measured by the ImageJ software.

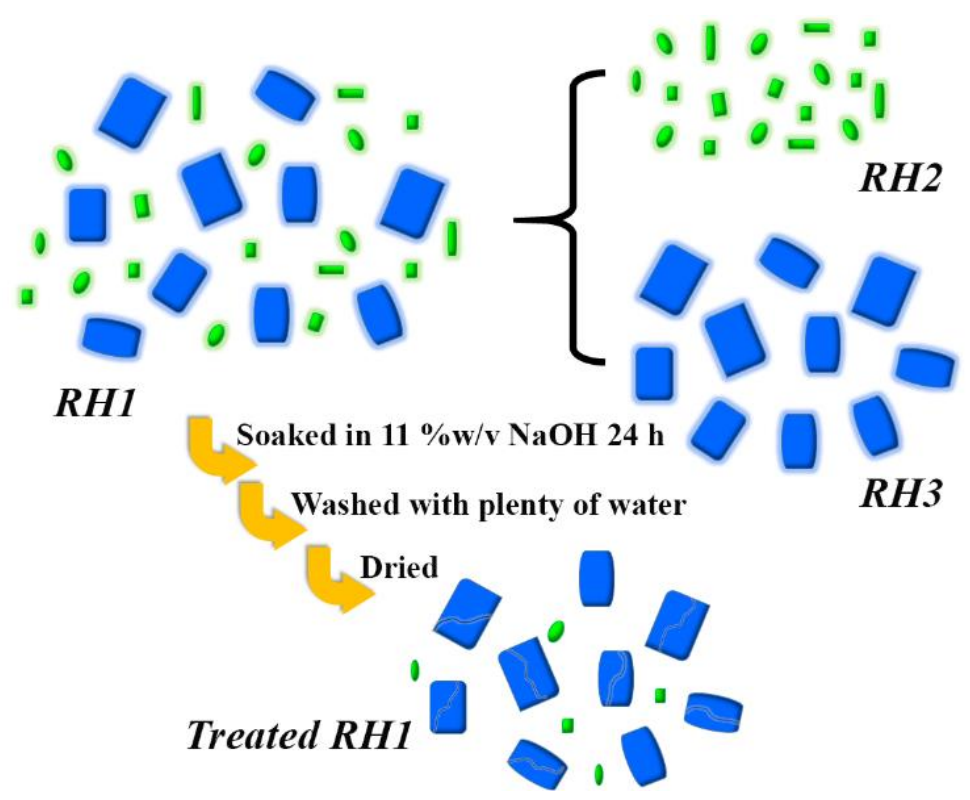

Figure 1. Illustration of alkaline treatment process.

\subsection{Preparation of thermoplastic cassava starch sheet}

Cassava starch (50 g) and glycerol (22.5 g) was mixed to prepare thermoplastic cassava starch (TPS) [7,8]. The amount of RH added to the starch/glycerol mixture was varied at 5 , 10,15 , and $20 \mathrm{wt} \%$ based on the weight of starch. Compression molding (KT-7014 produced 
by Kao Tieh Ltd., Taipei, Taiwan) was used to prepare the neat TPS and composite sheets at $160^{\circ} \mathrm{C}$ for $20 \mathrm{~min}$ with a pressure of $250 \mathrm{~kg} / \mathrm{cm}^{2}$.

\subsection{Characterization}

Scanning electron microscopy (SEM) and energy dispersive X-ray micro analysis (SEM$E D X)$. The morphologies of samples were determined using SEM (SEM-Quanta 400). The morphology of RH, cryo-fractured surfaces (the samples were immersed in liquid $\mathrm{N}_{2}$ and subsequently broken), and tensile-fractured surfaces of thermoplastic cassava starch composites were observed by SEM. The specimen was coated with a thin layer of gold. Untreated and treated RH samples were analyzed for microstructure and elemental compositions.

Fourier-transform infrared spectroscopy (FTIR). The FTIR spectra of the films were recorded on a Bruker Tensor 27 Fourier transform infrared spectrometer in attenuated total reflectance (ATR) mode using an accessory with a diamond crystal. The FTIR spectra of RH prepared as pellets and TPS composites were recorded in the range of $4000-600 \mathrm{~cm}^{-1}$ with 512 and 64 consecutive scans, respectively, using a resolution of $4 \mathrm{~cm}^{-1}$.

Thermogravimetric analysis (TGA). Thermal decomposition of RH and thermoplastic cassava starch composites was determined using the PerkinElmer TGA7. The analyses were conducted at a heating rate of $10^{\circ} \mathrm{C} / \mathrm{min}$ from $50-600^{\circ} \mathrm{C}$ in a nitrogen atmosphere.

Brunauer-Emmett-Teller (BET). The surface area of RH samples was determined by a static volumetric $\mathrm{N}_{2}$ gas adsorption method (ASAP 2460 and ASAP 2060, Micrometrics, USA).

Mechanical properties. Specimens were cut according to ASTM standard D638-03, type IV (width $=6 \mathrm{~mm}$, distance between grip $=65 \mathrm{~mm}$, and thickness of sample $=2.23 \pm 0.23$ $\mathrm{mm})$. Determination of tensile strength and elongation at break was carried out with a 
Universal Testing Machine (Instron 3365) equipped with a $100 \mathrm{~N}$ load cell and operated at a cross-head speed of $50 \mathrm{~mm} / \mathrm{min}$. The samples were kept for 7 days in a desiccator before testing. The measurements were taken at $25^{\circ} \mathrm{C}$ and ten specimens were determined per composite formulation.

Water absorption. The method of determination was modified from Yew et al. [25]. Samples $(10 \mathrm{~mm} \times 10 \mathrm{~mm})$ were dried in an oven at $80^{\circ} \mathrm{C}$ for $24 \mathrm{~h}$. The dried samples were immersed in water at room temperature for $24 \mathrm{~h}$. After taking out of the water, they were quickly removed excess water on the surface. The weight gain of starch sheets was measured using Equation (1) [26]:

Water absorption $(\%)=\left(w_{\mathrm{a}}-w_{0}\right) \times 100 / w_{0}$

where $w_{\mathrm{a}}$ was the weight of the sample at the absorbing equilibrium and $w_{0}$ was the initial dry weight of the sample.

Soil burial test. To obtain degraded samples, a soil burial test was carried out indoor using a procedure from Boonsuk et al. [27]. Briefly, the samples were cut into squares $10 \mathrm{~mm}$ $\times 10 \mathrm{~mm}$, dried in an oven at $80^{\circ} \mathrm{C}$ for $24 \mathrm{~h}$, weighed, and buried in soil in separate $500 \mathrm{~mL}$ cups. Six specimens were tested per composite formulation. The soil was watered with $10 \mathrm{~mL}$ every other day. Samples were buried for 1 week and 4 weeks. The degraded starch sheets were taken carefully from the soil and gently and quickly washed with water using a paint brush to remove soil. The degraded samples were dried at $80^{\circ} \mathrm{C}$ for $24 \mathrm{~h}$. The weight losses of the degraded samples were calculated using Equation (2): 
Weight loss $(\%)=\left(w_{0}-w_{\mathrm{d}}\right) \times 100 / w_{0}$

where $w_{0}$ and $w_{\mathrm{d}}$ were the weight of the dried sample before and after soil burial, respectively.

\section{Results and discussions}

\subsection{Untreated and treated rice husks}

\subsubsection{Morphology}

The SEM images of untreated RH (RH1, RH2, and $R H 3)$ and treated $R H 1$ are shown in and Figure 2. $R H 1$ consisted of $R H 2(48.8+3.6 \mathrm{wt} \%)$ and $R H 3(51.2+3.6 \mathrm{wt} \%)$. Treated $R H 1$ $(55.9 \pm 3.8 \mathrm{wt} \%$ based on weight of $R H 1)$ was prepared from $R H 1$ (Figure 1). The average sizes in length of $R H 1, R H 2, R H 3$, and treated $R H 1$ were $204 \pm 132,147 \pm 69,358 \pm 101$, and $236 \pm 115 \mu \mathrm{m}$, respectively. The outer surface of particles of untreated RH (Figure 2(e)) exhibited linear ridges while the inner surface was flatter (Figure $2(\mathrm{~g})$ ). The outer surface of untreated RH in the present study was consistent with previous observations [21,28]. Cracks, indicated by a yellow arrow (Figure 2(e)), were observed in the outer surface of untreated RH. After alkaline treatment, treated $R H 1$ exhibited more cracks and holes developed in the outer surfaces (Figure 2(f)) while the inner surface was smoother (Figure 2(h)). These morphological characteristics were due to the removal of hemicellulose $[24,29]$ and lignin [30]. An increase of outer surface roughness was obtained after the alkaline treatment [7,16,31,32]. 

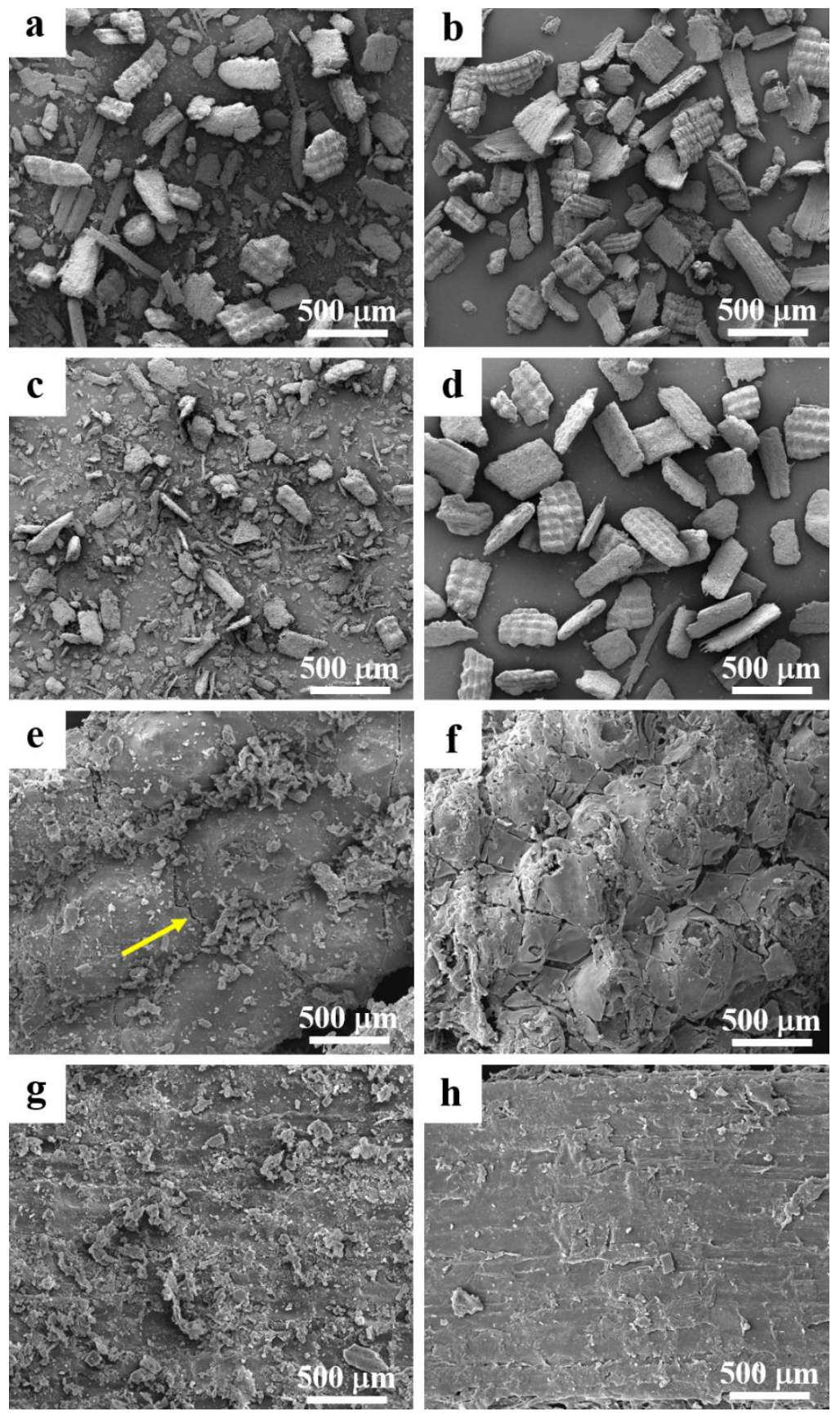

Figure 2. SEM images of (a) $R H 1$, (b) treated $R H 1$, (c) $R H 2$, (d) $R H 3$, (e) outer and (g) inner surfaces of untreated RH, and (f) outer and (h) inner surfaces of treated RHI.

\subsubsection{Structure}

FTIR spectra of untreated RH and alkaline treated RH are shown in Figure S1 in the Supporting Information. In the spectra of all samples, the peak located $\approx 3336 \mathrm{~cm}^{-1}$ was obtained from the $-\mathrm{OH}$ stretching of free $-\mathrm{OH}$ groups and hydrogen bonded $-\mathrm{OH}$ groups in 
cellulose fibers [33]. The peak at $1732 \mathrm{~cm}^{-1}$, observed in the spectra of untreated RH, was attributed to a carbonyl group of hemicellulose (indicated by arrow in the spectrum of $R H 3$ ) [34]. However, this peak disappeared in the spectrum of treated RH1. This result confirmed the removal of hemicellulose. The peak at $1513 \mathrm{~cm}^{-1}$ was derived from the $\mathrm{C}=\mathrm{C}$ stretching of lignin [35]. It has been reported that the alkaline treatment using $10 \mathrm{wt} \% \mathrm{NaOH}$ of bamboo fibers resulted in the partial removal of lignin and hemicellulose [36]. The peaks around 1025 $\mathrm{cm}^{-1}[37]$ and $790 \mathrm{~cm}^{-1}[38]$ related to the $\mathrm{O}-\mathrm{Si}-\mathrm{O}$ bonds in $\mathrm{SiO}_{2}$ of untreated $\mathrm{RH}$ and treated $R H 1$. Interestingly, the intensity of the $-\mathrm{OH}$ peak at $\approx 3336 \mathrm{~cm}^{-1}$ was greater in the spectrum of treated $\mathrm{RH} 1$ than those of untreated $\mathrm{RH}$. This effect might be attributed to expose of $-\mathrm{OH}-$ rich fibrils of the inner structure after removal of hemicellulose and lignin. However, Royan et al. reported a reduction of peak intensity of $-\mathrm{OH}$ groups after alkaline treatment $(2 \% \mathrm{w} / \mathrm{v}$ $\mathrm{NaOH}$ ) possibly due to the chemical reaction of accessible $-\mathrm{OH}$ groups with $\mathrm{NaOH}$ [16]. Alkaline treatment produced a smoother inner surface which revealed the fibrils (Figure 2(h)) and made $-\mathrm{OH}$ groups more accessible. The removal of hemicellulose and lignin caused the formation of new hydrogen bonds between cellulose chains [39].

\subsubsection{Thermal analysis}

The thermal behaviors of untreated $\mathrm{RH}$ and treated $\mathrm{RH} 1$ were investigated by TGA. In the TGA and derivative thermogravimetric (DTG) thermograms of untreated RH and treated RH1, three steps of weight loss were observed (Figure 3). The initial weight loss between $50^{\circ} \mathrm{C}$ and $130^{\circ} \mathrm{C}$ was attributed to moisture vaporization. The second decomposition step, observed in all untreated RH but not treated $R H 1$, located between $240^{\circ} \mathrm{C}$ and $325^{\circ} \mathrm{C}$ was attributed to the thermal decomposition of hemicellulose $[19,40,41]$ and glycosidic links of cellulose $[19,41]$. It has been reported that the degradation of cellulose, hemicellulose, and lignin took place within the temperature range of $200-400^{\circ} \mathrm{C}$ [42-44]. The absence of the 
second decomposition step in treated $\mathrm{RH} 1$ indicated its hemicellulose-free nature, which was consistent with FTIR spectrum [45]. The third step, between $330^{\circ} \mathrm{C}$ and $400^{\circ} \mathrm{C}$, was attributed to the degradation of cellulose $[40,46]$. It was reported that a peak at $360^{\circ} \mathrm{C}$ was due to the thermal decomposition of $\alpha$-cellulose (crystalline cellulose) $[19,20,41,47]$ and lignin degradation [48]. The residual weight of $R H 2$ was the highest which could be due to the high amount of $\mathrm{SiO}_{2}$, while the residue weight of treated $\mathrm{RHI}$ was the lowest possibly due to the degradation of RH by high alkaline solution.
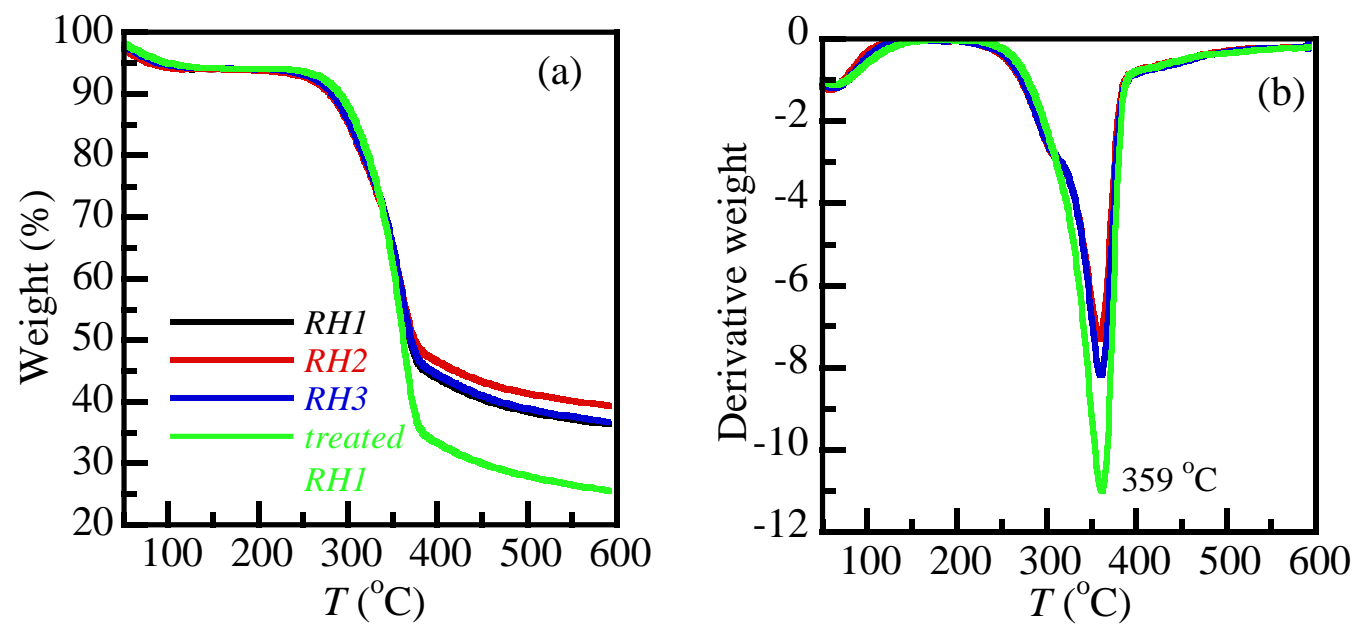

Figure 3. (a) TGA and (b) DTG thermograms of untreated RH (RH1, $R H 2$, and $R H 3)$ and treated RH1.

\subsubsection{Elemental analysis}

Park et al. used field-emission SEM and SEM-EDX to study the distribution of $\mathrm{SiO}_{2}$ in untreated $\mathrm{RH}$ and they concluded that $\mathrm{SiO}_{2}$ was predominantly located at the tips and shoulders of the ridges, and was present in lower amounts in other regions of RH [21]. The high $\mathrm{SiO}_{2}$ content on the outer surface provides strength and stiffness to the husk $[21,49]$. In this work, the SEM-EDX images of outer, inner, and cross sectional surfaces of untreated RH 
(either $R H 1, R H 2$, or $R H 3$ ) and treated $R H 1$ are shown in Figure 4 and 5, respectively, while the associated elemental contents are listed in Table 1.

Table 1. Carbon, oxygen, silicon, and sodium contents in untreated RH and treated RHI obtained from SEM-EDX.

\begin{tabular}{|l|c|c|c|c|c|c|c|c|}
\hline \multirow{1}{*}{ Surface } & \multicolumn{7}{c|}{ Element (\%) } \\
\cline { 2 - 9 } & \multicolumn{7}{|c|}{ Untreated RH } & \multicolumn{5}{c|}{ Treated RHI } \\
\cline { 2 - 9 } & $\mathrm{C}$ & $\mathrm{O}$ & $\mathrm{Si}$ & $\mathrm{Na}$ & $\mathrm{C}$ & $\mathrm{O}$ & $\mathrm{Si}$ & $\mathrm{Na}$ \\
\hline Outer & 30.8 & 44.6 & 24.6 & 0 & 30.9 & 45.5 & 23.5 & 0.1 \\
\hline Inner & 45.9 & 43.3 & 10.8 & 0 & 56.2 & 43.3 & 0.3 & 0.2 \\
\hline Cross section $^{\mathrm{a}}$ & $\checkmark$ & $\checkmark$ & $\checkmark$ & 0 & $\checkmark$ & $\checkmark$ & $\checkmark$ & $\checkmark$ \\
\hline
\end{tabular}

a The presence of the element is represented by using ' $\checkmark$ '.

The percentage of elements was not calculated for cross sections of samples (Figure $4(\mathrm{i}, \mathrm{j})$ and $5(\mathrm{i}, \mathrm{j}))$ because the carbon tape used to fix $\mathrm{RH}$ produced a carbon signal that altered the percentage of carbon and other elements. The grinding process damaged the ridges and thus $\mathrm{SiO}_{2}$ was released from the ridges and deposited on the whole surfaces of untreated $\mathrm{RH}$ particles (Figure 4(a, e, and i)). The clean inner (Figure 5(e)) and cross sectional (Figure 5(i)) surfaces of treated $\mathrm{RH} 1$ confirmed that the removal of $\mathrm{SiO}_{2}$ by the alkaline treatment was incomplete. $\mathrm{SiO}_{2}$ was located densely on the outer surface of $\mathrm{RH}$. In contrast, Shrestha et al. used SEM-EDX elemental mapping to show that $\mathrm{SiO}_{2}$ was completely removed from $\mathrm{RH}$ pre-carbonized at $300{ }^{\circ} \mathrm{C}$ in air followed by washing with $4 \% \mathrm{w} / \mathrm{v} \mathrm{NaOH}[50]$. $\mathrm{NaOH}$ dissolved $\mathrm{SiO}_{2}$ and formed water soluble sodium silicate $\left(\mathrm{Na}_{2} \mathrm{SiO}_{3}\right)[50,51]$ which was 
washed out with water [50]. However, the $\mathrm{SiO}_{2}$ located at the outer surface of $\mathrm{RH}$ was not removed during the alkaline treatment.

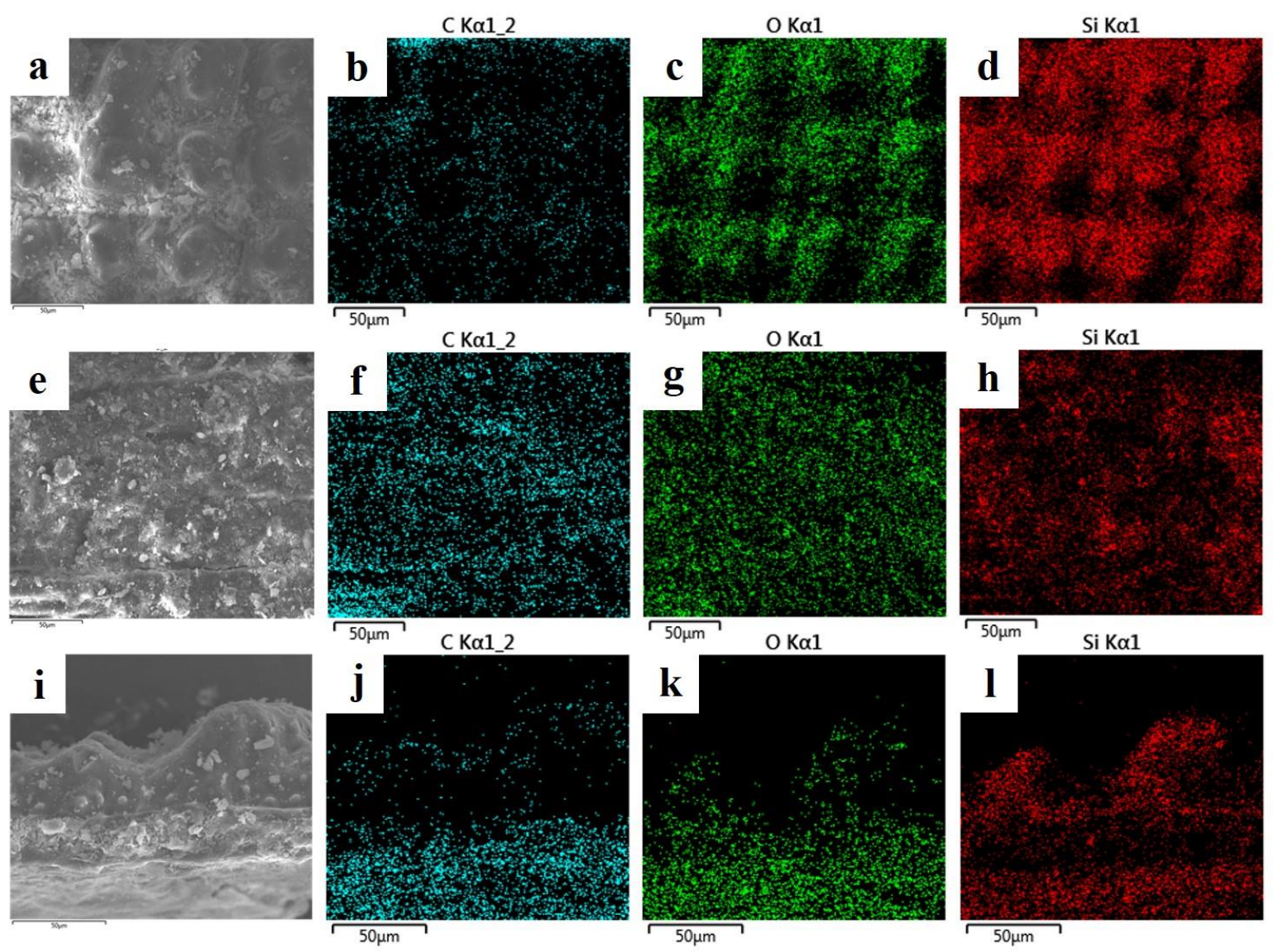

Figure 4. SEM-EDX images of untreated RH: (a)-(d) outer, (e)-(h) inner, and (i)-(l) cross sectional surfaces. 

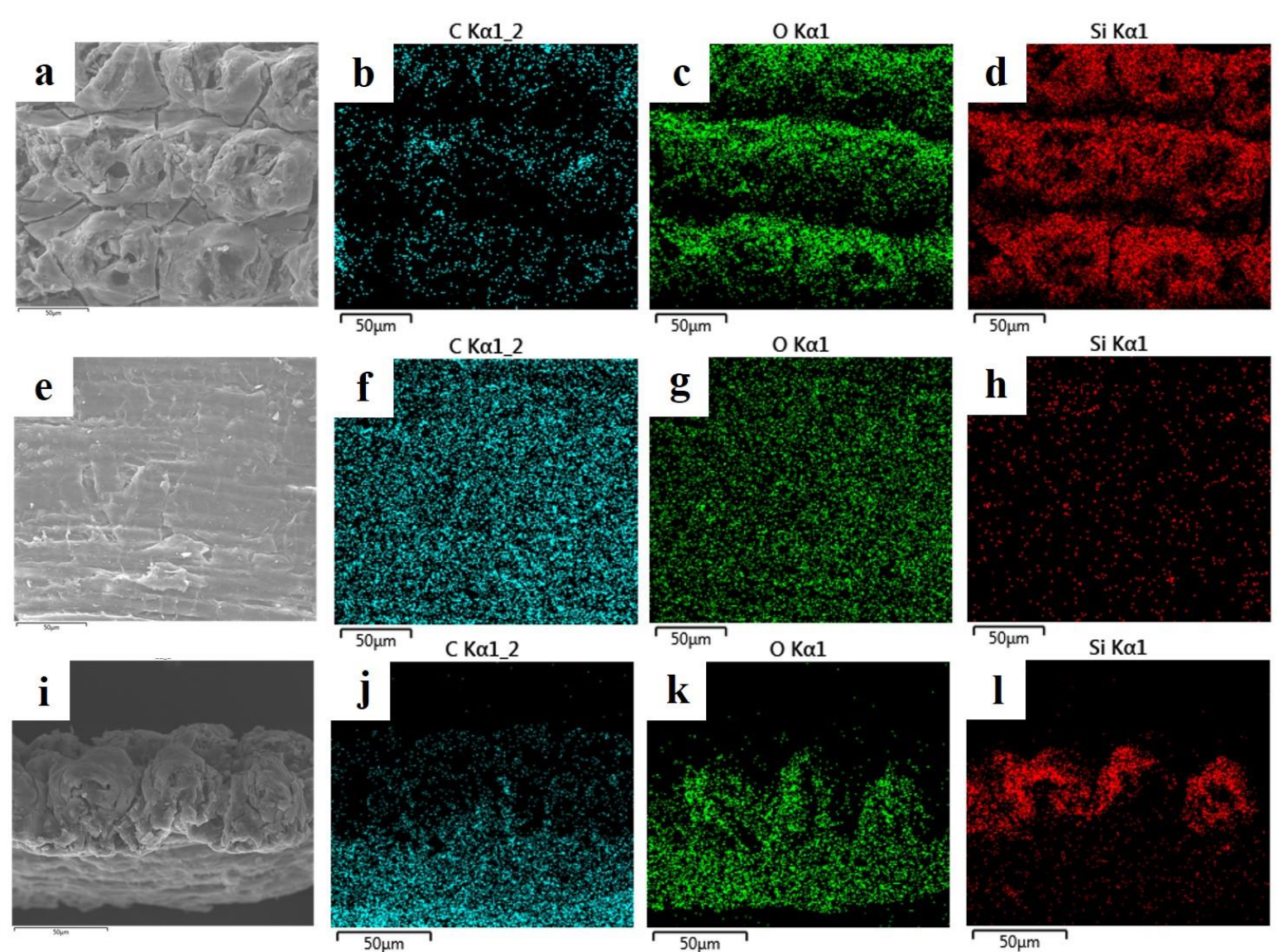

Figure 5. SEM-EDX images of treated RHI: (a)-(d) outer, (e)-(h) inner, and (i)-(l) cross sectional surfaces.

\subsubsection{Surface area}

The BET surface areas of $R H 1, R H 2, R H 3$, and treated $R H 1$ were $1.88,3.77,1.64$, and $1.45 \mathrm{~m}^{2} / \mathrm{g}$, respectively. $R H 2$ had the largest surface area and this was consistent with its particle size which was the smallest $(147 \pm 69 \mu \mathrm{m})($ Figure 2(c)). The surface area of treated RHI was lower than those of untreated $\mathrm{RH}$ due to the removal of $\mathrm{SiO}_{2}$ by alkaline treatment.

The cracks and holes in the outer and cross sectional surfaces of treated RHI did not affect its surface area. $\mathrm{NaOH}$ treatment of $R H I$ did not lead to the formation of micropores or mesopores [50]. Therefore, the surface area of treated $\mathrm{RH} 1$ was not greater after $\mathrm{NaOH}$ treatment. 


\subsection{Thermoplastic cassava starch/rice husk composites}

\subsubsection{Structure}

The TPS containing 0-20 wt $\%$ of all RH showed similar FTIR peaks (Figure S2 in the Supporting Information). The absorption peaks located $\approx 3284,2928-2888,1648,1413,1149$ and 1107,995 , and $759 \mathrm{~cm}^{-1}$ were respectively attributed to the $-\mathrm{OH}$ stretching vibration [52,53], the stretching vibration of $-\mathrm{CH}_{2}$ [52,53], the $-\mathrm{OH}$ bending of bound water [52], the bending of $-\mathrm{CH}_{2}[52]$, the $\mathrm{C}-\mathrm{O}$ stretching in $\mathrm{C}-\mathrm{O}-\mathrm{H}$ [53], the $\mathrm{C}-\mathrm{O}$ stretching in the $\mathrm{C}-\mathrm{O}-\mathrm{C}$ groups [53] of glycosidic linkage [54], and the $\mathrm{C}-\mathrm{O}$ bending in $\mathrm{C}-\mathrm{O}-\mathrm{C}$ groups of the anhydrous glucose ring [53]. The peaks around $1025 \mathrm{~cm}^{-1}$ [37] and $790 \mathrm{~cm}^{-1}$ [38] related to the $\mathrm{O}-\mathrm{Si}-\mathrm{O}$ bonds in $\mathrm{SiO}_{2}$. The peaks of $-\mathrm{OH}$ stretching vibration of neat TPS and TPS/RH composites appeared at similar position (Table S1 in the Supporting Information), possibly due to the dominating role of the matrix. However, in a related study, the $-\mathrm{OH}$ stretching vibration peak of the TPS/untreated luffa fiber was shifted to lower wave number compared to the neat TPS, thus providing direct evidence for the development of hydrogen bonding between the starch and the fiber [8].

\subsubsection{Morphology}

From this section onwards, the results of TPS/RHI and TPS/treated RHI composites were mainly compared for clarity. The results of TPS/RH2 and TPS/RH3 composites were shown in the Supporting Information. The cryo-fractured surfaces of TPS/RH1 and TPS/treated RH1 composites are shown in Figure 6 (Figure S3 in the Supporting Information displays images of the cryo-fractured surfaces of TPS/RH2 and TPS/RH3 composites). The sizes of all RH particles resemble the RH images in Figure 2. The enlarged SEM images of all TPS/RH composites are shown in Figure S4. No void was observed between the starch 
matrix and RH particles, suggesting a good interfacial interaction between $\mathrm{RH}$ and the matrix due to their similar chemical structure $[13,55]$.
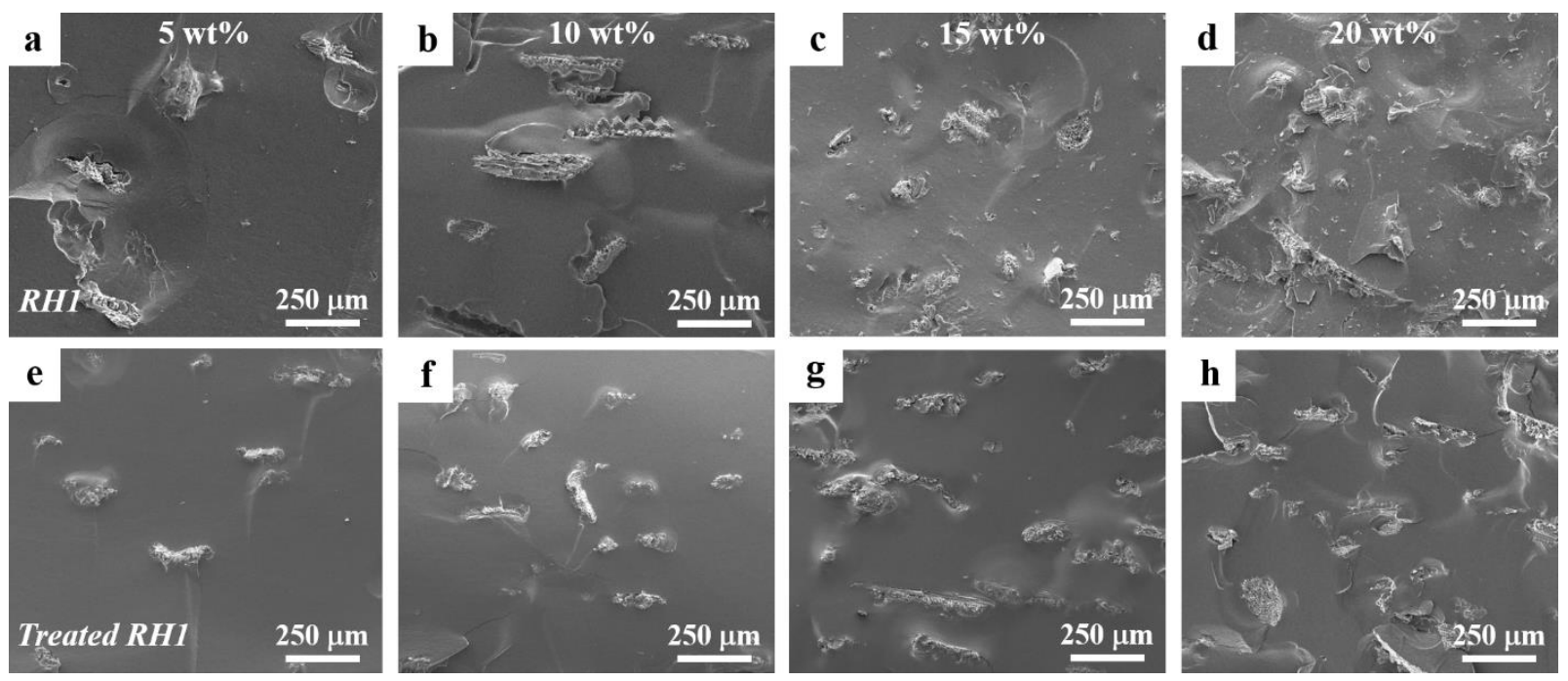

Figure 6. SEM images of cryo-fractured surfaces of TPS composites containing (a)-(d) $R H 1$ and (e)-(h) treated RH1. RH contents are indicated.

\subsubsection{Thermal analysis}

Most of the thermal degradation of TPS/untreated RH composites took place between $280^{\circ} \mathrm{C}$ and $400^{\circ} \mathrm{C}$ as shown in Figure 7 for neat TPS, TPS $/ R H 1$ and TPS/treated $R H 1$ composites (Figure S5 in the Supporting Information for TPS/RH2 and TPS/RH3 composites). The weight loss that occurred between $100^{\circ} \mathrm{C}$ and $200^{\circ} \mathrm{C}$ was attributed to the evaporation of water and glycerol, respectively [8]. The highest decomposition temperature of neat TPS took place at $336^{\circ} \mathrm{C}(0 \mathrm{wt} \% \mathrm{RH})$. All TPS/untreated $\mathrm{RH}$ composites showed an improvement in thermal stability of the composites up to $T \approx 350^{\circ} \mathrm{C}$ due to the enhanced thermal stability of hemicellulose and cellulose in untreated RH. This finding was in agreement with previous studies in similar systems $[8,9,55]$. 

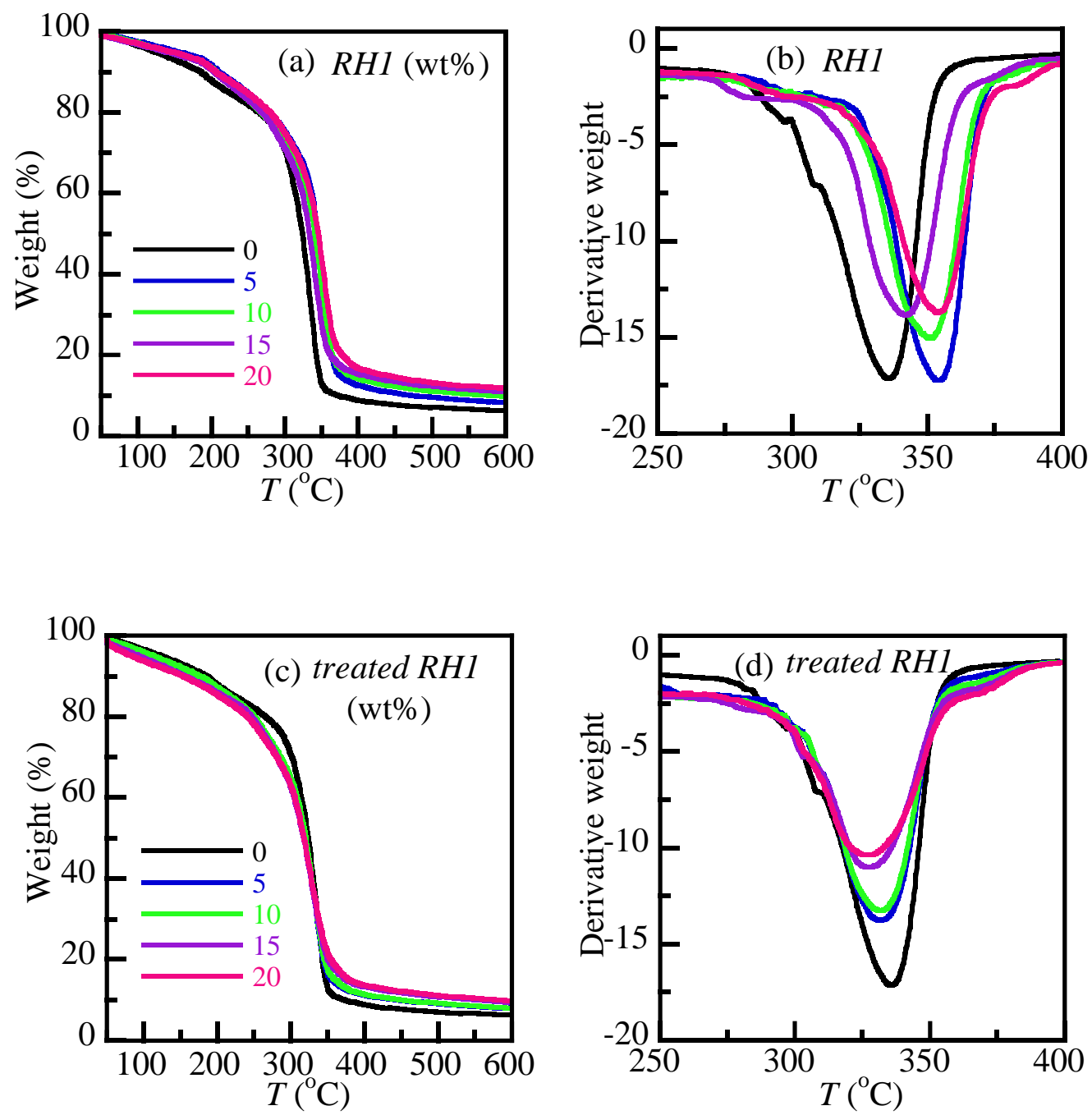

Figure 7. TGA thermograms and derivatives of (a)-(b) TPS/RHI and (c)-(d) TPS/treated RH1 composites.

The DTG peaks of all TPS/treated RHI composites were lower than that of neat TPS $\left(336^{\circ} \mathrm{C}\right)$, especially at high content of treated $R H 1(15$ and $20 \mathrm{wt} \%)\left(\approx 328^{\circ} \mathrm{C}\right)$. Treated $R H 1$ slightly reduced the thermal stability of TPS, possibly due to the more pronounced hydrophilicity of the surface. The residual weight at $T>400^{\circ} \mathrm{C}$ of TPS/treated RHI systematically increased with increment of treated RHI content (Figure 7(c)). It has been reported that thermal decomposition of phenol formaldehyde resin/treated RH composites 
was lower than that of a resin/untreated $\mathrm{RH}$ composite owing to the degradation of RH by 2 $\% \mathrm{w} / \mathrm{v} \mathrm{NaOH}[16]$. However, treated bagasse fiber with $1 \% \mathrm{w} / \mathrm{v} \mathrm{NaOH}$ reinforced in cassava starch composites slightly improved their thermal stability compared with neat TPS [7].

The residual weights of cassava starch-based composites at $600^{\circ} \mathrm{C}$ were compared with the neat TPS $(0 \mathrm{wt} \% \mathrm{RH})$ (Table 2$)$. The neat TPS showed a DTG peak at $336^{\circ} \mathrm{C}$ and its residual weight at $600^{\circ} \mathrm{C}$ was estimated at $8.01 \mathrm{wt} \%$. All TPS/untreated RH composites showed significantly increased residual weights at $600^{\circ} \mathrm{C}$, whereas the composites containing treated $\mathrm{RHI}$ consistently showed only marginally higher residual weight compared with the neat TPS, an effect that is in line with the low $\mathrm{SiO}_{2}$ content of the filler and the degradation of $\mathrm{RH}$ by alkaline treatment as previously stated. It was reported that the residual weight at $700^{\circ} \mathrm{C}$ of $\mathrm{RH}$ in nitrogen atmosphere was composed of carbonaceous products and $\mathrm{SiO}_{2}$ [28].

Table 2. DTG results and residual weights of the TPS/RH composites.

\begin{tabular}{|c|c|c|c|c|c|c|c|c|}
\hline \multirow{2}{*}{$\begin{array}{c}\text { RH content } \\
(\mathrm{wt} \%)\end{array}$} & \multicolumn{5}{|c|}{ DTG $\left({ }^{\circ} \mathrm{C}\right)$} & \multicolumn{3}{c|}{ Residual weight at $600^{\circ} \mathrm{C}(\%)$} \\
\cline { 2 - 9 } & RH1 & RH2 & RH3 & Treated RH1 & RH1 & RH2 & RH3 & Treated RH1 \\
\hline 5 & 354 & 349 & 347 & 332 & 8.43 & 8.32 & 8.46 & 8.01 \\
\hline 10 & 351 & 346 & 344 & 331 & 9.90 & 9.86 & 9.47 & 8.15 \\
\hline 15 & 343 & 345 & 344 & 327 & 11.05 & 11.06 & 10.53 & 9.54 \\
\hline 20 & 355 & 346 & 347 & 328 & 11.81 & 11.47 & 12.83 & 9.86 \\
\hline
\end{tabular}

\subsubsection{Mechanical properties}

As shown in Figure 8, the tensile strength in TPS/treated RHI (and to a lesser extent for TPS/RH1) composites increases with filler loading, reaching a value of $2.43 \mathrm{kPa}$ for 20 
wt $\%$ loading compared to $0.76 \mathrm{kPa}$ for the neat TPS. (Figure S6 in the Supporting Information displays the tensile strength for TPS/RH2 and TPS/RH3 composites, also suggesting a rather limited effect upon increasing the filler loading). Among TPS/untreated RH composites, TPS/RH2 composites showed the lowest tensile strength but the highest elongation at break. This behavior possibly stemmed from the smallest size $(147+69 \mu \mathrm{m})$ of the dispersed particles. In contrast, TPS/RHI composites showed the highest tensile strength due to the broad particle size distribution $(204 \pm 132 \mu \mathrm{m})$ of the $\mathrm{RH}$. The results were similar to those previously reported for tensile strength of the TPS/luffa composites at $10 \mathrm{wt} \%$ fiber [8]. The incorporation of treated $R H 1$ significantly increased tensile strength ( $220 \%$ at 20 $w t \%$ ) but decreased elongation at break of the TPS composites (Figure 8(b)) which points to improved matrix/filler load transfer presumably facilitated by the loss of hemicellulose and the rough outer surfaces after $\mathrm{NaOH}$-treatment $[16,22]$. The filaments of treated fibers were split after the alkaline treatment due to the dissolution of hemicellulose, thus improving the interfacial adhesion between fibers and matrix [29]. A number of previous studies reported that high fibers content of the composites resulted in improved tensile strength $[6,8,9,13,31,55]$. Edhirej et al. reported that TPS composites reinforced with untreated bagasse with size of $<300 \mu \mathrm{m}$ exhibited higher tensile strength compared with those reinforced with bagasse sized within 300-600 $\mu \mathrm{m}$ [6]. TPS/RHI and TPS/treated RHI composites showed similar levels of elongation at break (Figure 8(b)). 

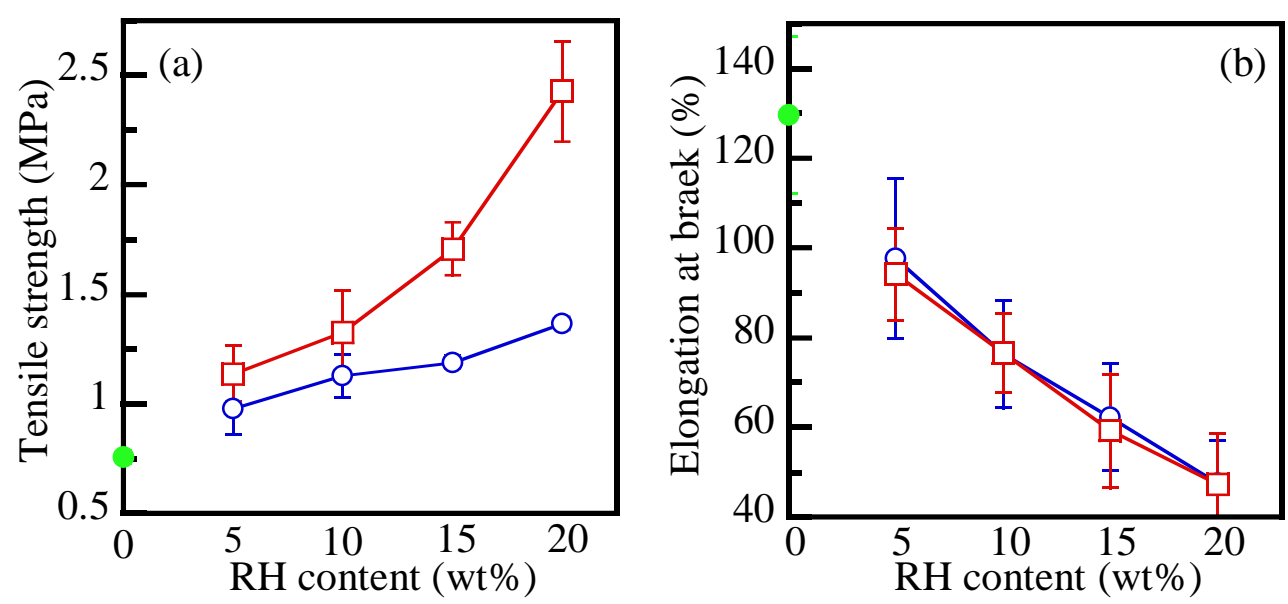

Figure 8. (a) Tensile strength and (b) elongation at break of neat TPS (filled circle), TPS/RH1 (open circles), and TPS/treated RHI (open squares) composites.

The fractured surfaces of TPS composites containing $15 \mathrm{wt} \%$ obtained from tensile testing are shown in Figure 9 for TPS/RHI and TPS/treated $R H 1$ composites. It was found that only starch matrix surrounded by treated RHI was torn (Figure 9(b)) due to the good adhesion between starch matrix and treated RH1. The enhancement in tensile strength after alkaline treatment points to more effective fiber/matrix load transfer [56,57] as a result of stronger interfacial interactions arising from favorable topological and wetting contributions [58-60]. In principle, interface bonding in fiber reinforced composites takes place via electrostatic forces, chemical bonding and mechanical interlocking mechanisms [61]. Alkaline treatment increases crystallinity index of fibers, enhancing formation of hydrogen bonds between cellulose chains and hence chemical bonding between the fibers in composites [62-64]. The mechanical interlocking mechanism is dominant when the surface of the fiber is rough [56]. 

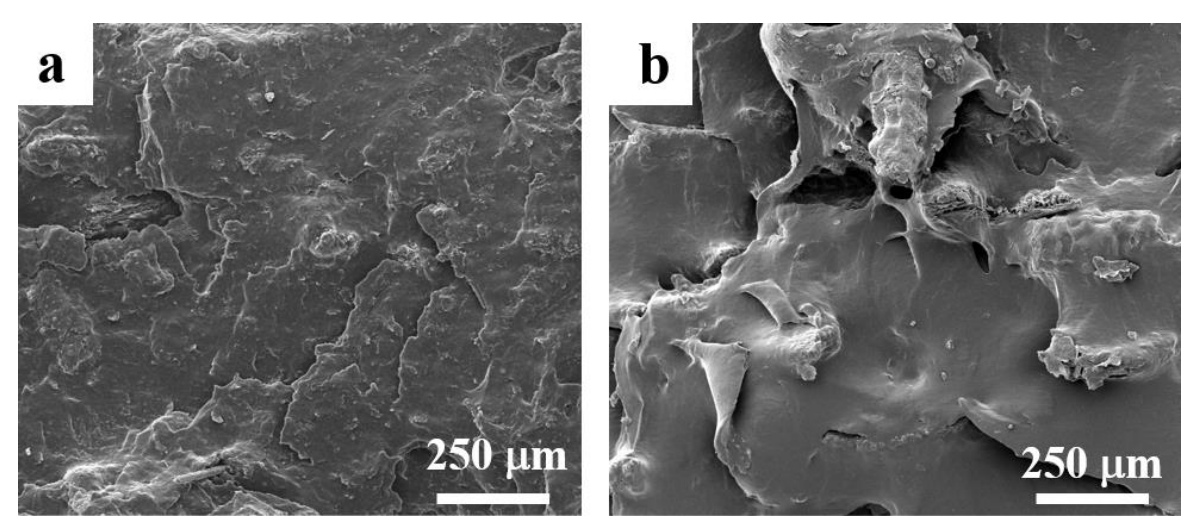

Figure 9. SEM images of fractured surfaces of TPS composites containing $15 \mathrm{wt} \%$ of (a) RHI and (b) treated RHI.

\subsubsection{Water absorption}

The water absorption for TPS/RHI and TPS/treated RHI composites contain various amounts of RH is shown in Figure 10 (Figure S7 in the Supporting Information for TPS/untreated RH composites). The first step of water uptake was from the direct capture of water molecules through microgaps between polymer chains. Secondly, water molecules directly diffused through capillary transport into the gaps and flaws at the interfaces between the fiber and matrix [65]. As shown in Figure 10, incorporation of treated RH1 resulted in substantial enhancements in water absorption, reaching a maximum value of $365 \mathrm{wt} \%$ at 15 wt $\%$ loading, compared to $124 \mathrm{wt} \%$ for the neat TPS. In contrast, addition of 5, 10, 15 and 20 wt $\%$ of $R H 1$ resulted in a marginal decrease in water absorption. For comparison, as shown in Figure S7 in the Supporting Information, it was noted that within the TPS/RH2 series, the highest water absorption of $177 \mathrm{wt} \%$ was observed at $10 \mathrm{wt} \%$ loading, while within the TPS/RH3 series, the highest water absorption of $224 \mathrm{wt} \%$ was observed at $15 \mathrm{wt} \%$ loading. Note that previous studies reported that the addition of untreated fibers in starch composites increased the water resistance as a direct consequence of their hydrophobic nature [3,9,13,55]. Regarding TPS/treated RHI composites, high water absorption behavior might be attributed to the improved hydrophilicity of the fillers (indicated by the pronounced $-\mathrm{OH}$ 
peak in the FTIR spectrum), the presence of cracks that functioned as additional water channels and facilitated water diffusion, and the fiber swelling after the alkaline immersion [16]. These phenomena increased the hydrophilic nature of treated $R H 1$ and thus raised accessibility of water molecules. The TPS/treated RHI composites loaded at $20 \mathrm{wt} \%$ contained numerous filler particles that might create a network that blocked the diffusion of water molecules and limited the water storage capacity of the composite. By virtue of their remarkable water absorption capabilities, the TPS/treated $R H 1$ biocomposites carry promise for the development of novel highly absorbent materials that show certain advantages compared to their petroleum-based counterparts in terms of their improved biodegradation, and their non-toxic nature $[66,67]$.

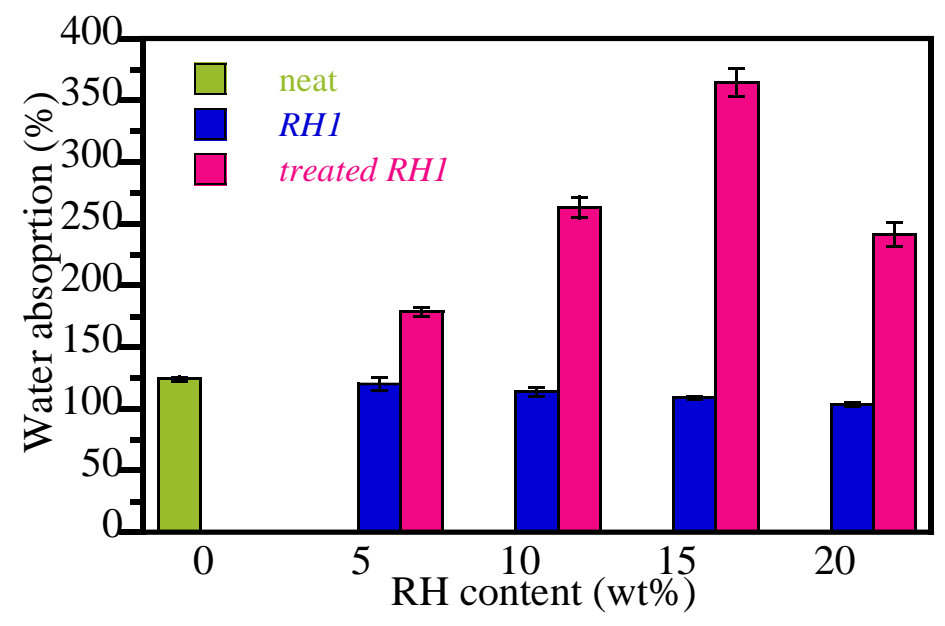

Figure 10. Water absorption of neat TPS, TPS/RH1 and TPS/treated RH1 composites.

\subsubsection{Soil burial test}

All TPS/RH composites were buried in soil after 1 week and 4 weeks. The weight loss for neat TPS, TPS/RH1 and TPS/treated RH1 composites are plotted in Figure 11 (Figure S8 in the Supporting Information for TPS/untreated RH composites). Among the TPS/untreated 
RH composites, all TPS/RH2 composites showed the highest weight loss following a 4-week burial period (Figure S8(b)). Higher amounts of untreated RH marginally decreased the weight loss of the composites following a 4-week burial period (Figure 11(b)). It has been reported that increasing the percent okra fibers in the composites delayed the degradation rate, as a consequence of the slower degradation kinetics of the okra cellulosic fibers compared with the matrix [3]. The neat TPS and TPS/treated RHI composites showed remarkably high weight losses after 1 week (Figure 11(a)) and had similar weight losses after 4 weeks (Figure 11(b)). The weight loss of TPS/treated RHI composites was the highest at 4 weeks which could be attributed to the fact that treated $\mathrm{RH} 1$ was more hydrophilic than untreated RH. The similarity at 4 weeks in the weight loss of neat TPS and TPS/treated RH1 indicated the good biodegradability of the alkaline treated RHI composites. The TPS/treated RH1 composite combined superior mechanical properties with excellent biodegradability.

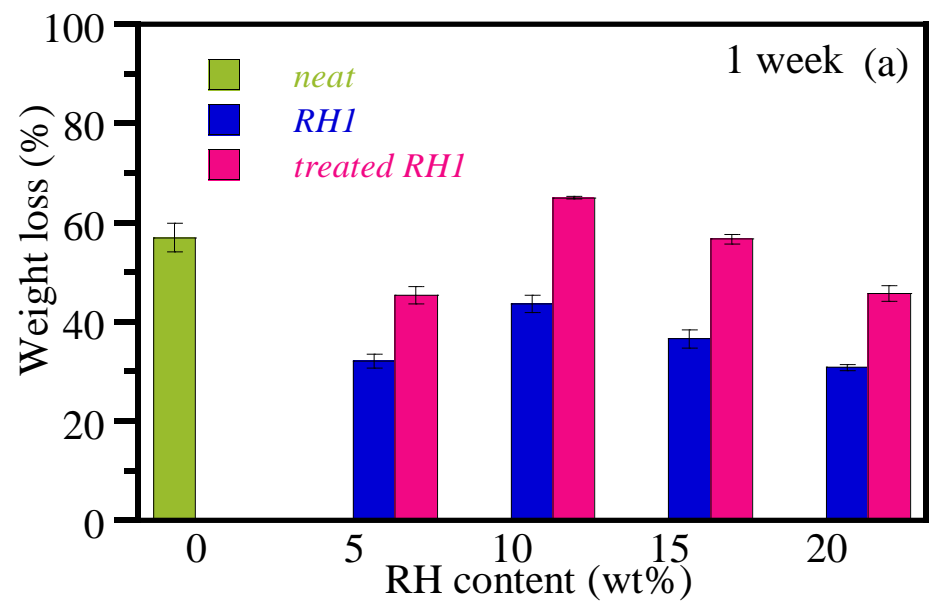




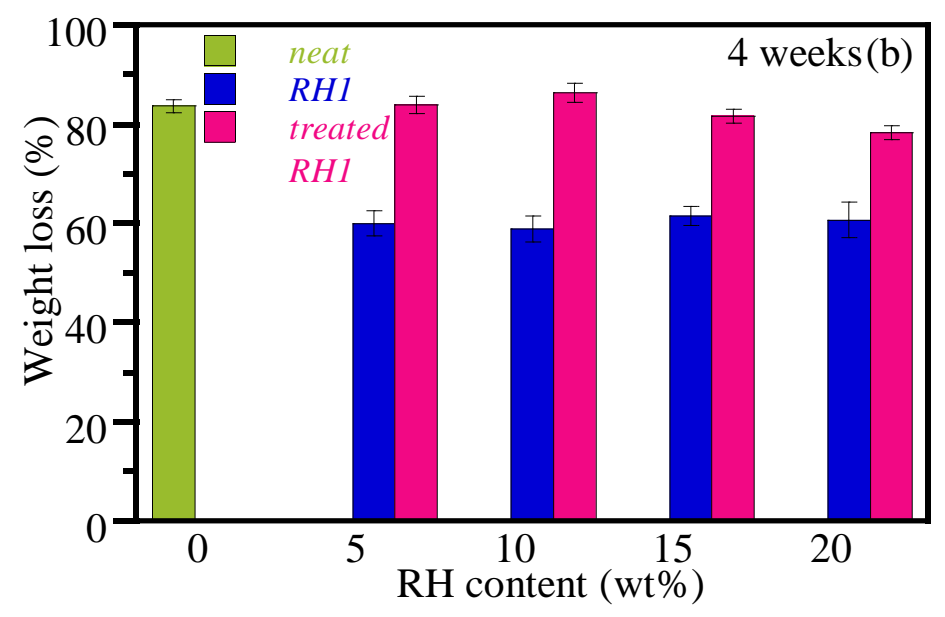

Figure 11. Weight loss after burial in soil (a) 1 week and (b) 4 weeks of neat TPS and TPS/RH composites containing $R H 1$ and treated $R H 1$ with RH loadings of 5-20 wt $\%$.

\section{Conclusions}

The incorporation of high alkaline treated $\mathrm{RH}$ within TPS matrix is an effective strategy to generate biocomposites with advanced properties over TPS/untreated RH composites. High alkaline treatment of RH resulted in the partial removal of hemicellulose and lignin, giving rise to an increased number of $-\mathrm{OH}$ rich-fibrils on the filler surface. TPS reinforced with alkaline treated $\mathrm{RH}$ showed substantially improved tensile strength, an effect that points to effective matrix/filler load transfer that can be traced back to improved matrixfiller interface interactions. At the same time, this class of TPS/treated RH composites retained the excellent biodegradable behavior of the pristine matrix and showed enhanced water absorption capability. The various sizes of untreated RH in TPS composites had no effect on tensile strength up to $20 \mathrm{wt} \% \mathrm{RH}$, but affected the water absorption at $15 \mathrm{wt} \% \mathrm{RH}$ and slightly affected the biodegradation in 4 weeks. 


\section{Acknowledgement}

This work was supported by Prince of Songkla University, Thailand (contract number SCI610563S). 


\section{References}

[1] T. Jiang, Q. Duan, J. Zhu, H. Liu, L. Yu, Starch-based biodegradable materials: challenges and opportunities, Advanced Industrial and Engineering Polymer Research 3 (2020) 8-18. https://doi.org/10.1016/j.aiepr.2019.11.003.

[2] Z. Sun, Progress in the research and applications of natural fiber-reinforced polymer matrix composites, Sci. Eng. Compos. Mater. 22 (2018) 835-846.

https://doi.org/10.1515/secm-2016-0072.

[3] A. Guleria, A.S. Singha, R.K. Rana, Mechanical, thermal, morphological, and biodegradable studies of okra cellulosic fiber reinforced starch-based biocomposites, Adv. Polym. Tech. 1 (2018), DOI 10.1002/adv.21646. https://doi.org/10.1002/adv.21646.

[4] K.H. Son, I.S. Kim, Effects of plasticizer on the mechanical properties of kenaf/starch bio-composites, Fiber. Polym. 14 (2013) 2135-2140. DOI 10.1007/s12221-013-2135-7. [5] Y. Chen, L. Yu, X. Ge, H. Liu, A. Ali, Y. Wang, L. Chen, Preparation and characterization of edible starch film reinforced by laver, Int. J. Biol. Macromol. 129 (2019) 944-951. https://doi.org/10.1016/j.ijbiomac.2019.02.045.

[6] A. Edhirej, S.M. Sapuan, M. Jawaid, N.I. Zahari, Preparation and characterization of cassava bagasse reinforced thermoplastic cassava starch, Fiber. Polym. 18 (2017) 162-171. DOI 10.1007/s12221-017-6251-7.

[7] K. Kaewtatip, J. Thongmee, Preparation of thermoplastic starch/treated bagasse fiber composites, Starch/Stärke 66 (2014) 724-728. https://doi.org/10.1002/star.201400005. [8] K. Kaewtatip, J. Thongmee, Studies on the structure and properties of thermoplastic starch/luffa fiber composites, Mater. Des. 40 (2012) 314-318. https://doi.org/10.1016/j.matdes.2012.03.053. 
[9] A. Wattanakornsiri, K. Pachana, S. Kaewpirom, P. Sawangwong, C. Migliaresi, Green composites of thermoplastic corn starch and recycled paper cellulose fibers, Songklanakarin J. Sci. Technol. 33 (2011) 461-467.

[10] A. Grylewicz, T. Spychaj, M. Zdanowicz, Thermoplastic starch/wood biocomposites processed with deep eutectic solvents, Compos. Part A Appl. Sci. Manuf. 121 (2019) 517524. https://doi.org/10.1016/j.compositesa.2019.04.001

[11] A.I. García, A.M. García, S.F. Bou, Study of the influence of the almond shell variety on the mechanical properties of starch-based polymer biocomposites, Polymers 12 (2020) 2049. Doi:10.3390/polym12092049

[12] A.M. Nafchi, M. Moradpour, M. Saeidi, A.K. Alias, Thermoplastic starches: properties, challenges, and prospects, Starch/Stärke 65 (2013) 61-72. DOI: 10.1002/star.201200201. [13] V. Saetun, C. Chiachun, S.A. Riyajan, K. Kaewtatip, Green composites based on thermoplastic starch and rubber wood sawdust, Polym. Compos. 38 (2017) 1063-1069. https://doi.org/10.1002/pc.23669.

[14] Y. Zhou, M. Fan, L. Chen, Interface and bonding mechanisms of plant fibre composites: an overview, Composites Part B: Engineering 101 (2016) 31-45. https://doi.org/10.1016/j.compositesb.2016.06.055. [15] Z. Sun, Progress in the research and applications of natural fiber-reinforced polymer matrix composites, Sci. Eng. Compos. Mater. 25 (2018) 835-846.

[16] N.R.R. Royan, A.B. Sulong, N.Y. Yuhana, R.S. Chen, M.H.A. Ghani, S. Ahmad, 2018. $\mathrm{UV} / \mathrm{O}_{3}$ treatment as a surface modification of rice husk towards preparation of novel biocomposites LoS ONE, 13:e0197345. http://doi.org/10.1371/journal.pone0197345. 
[17] V. Gerardi, F. Minelli, D. Viggiano, Steam treated rice industry residues as an alternative feedstock for the wood based particleboard industry in Italy, Biomass Bioenerg. 14 (1998) 295-299. https://doi.org/10.1016/S0961-9534(97)10042-3.

[18] P. Leiva, E.M. Ciannamea, R.A. Ruseckaite, P.M. Stefani, Medium-density particleboards from rice husks and soybean protein concentrate, J. Appl. Polym. Sci. 106 (2007) 1301-1306. https://doi.org/10.1016/j.biortech.2009.08.084.

[19] G. Mansaray, A.E. Ghaly, Thermal degradation of rice husks in nitrogen atmosphere, Bioresour. Technol. 65 (1998)13-20. https://doi.org/10.1016/S0960-8524(98)00031-5.

[20] P.M. Stefani, D. Garcia, J. Lopez, A. Jimenez, Thermogravemetric analysis of composites obtained from sintering of rice husk-scrap tire mixtures, J. Therm. Anal. Calorim. 81 (2005) 315-320. https://doi.org/10.1007/s10973-005-0785-4.

[21] B.D. Park, S.G. Wi, K.H. Lee, A.P. Singh, T.H. Yoon, Y.S. Kim, Characterization of anatomical features and silica distribution in rice husk using microscopic and microanalytical techniques, Biomass Bioenerg. 25 (2003) 319-327. https://doi.org/10.1016/S09619534(03)00014-X.

[22] M.H.A. Ghani, N.R.R. Royan, S.M. Kang, A.B. Sulong, A. Ahmad, Effect of alkaline treated rice husk on the mechanical and morphological properties of recycled HDPE/RH composite, Journal of Applied Science and Agriculture 10 (2015) 138-144.

[23] J. Geouge, M.S. Sreekala, S.A. Thomas, A review on interface modification and characterization of natural fiber reinforced plastic composites, Polym. Eng. Sci. 41 (2001) 1471-1485. DOI: 10.1002/pen.10846.

[24] B.S. Ndazi, S. Karlsson, C. Nyahumwa, J. Tesha, Chemical and thermal stability of rice husks against alkali treatment, BioResources 3 (2007)1267-1277. 
[25] B.S. Yew, M. Muhamad, S.B. Mohamed, F.H. Wee, Effect of alkaline treatment on stability of coir fiber polymer composites. Sain Malaysian, 48 (2019) 653-659.

DOI: $10.17576 /$ jsm-2019-4803-19.

[26] S.D. Yoon, Cross-linked potato starch-based blend films using ascorbic acid as a plasticizer, J. Agric. Food Chem. 62 (2014) 1755-1764. https://doi.org/10.1021/jf4024855.

[27] P. Boonsuk, A. Sukolrat, K. Kaewtatip, S. Chantarak, A. Kelarakis, C. Chaibundit Modified cassava starch/poly(vinyl alcohol) blend films plasticized by glycerol: structure and properties, J. Appl. Polym. Sci. 135 (2020) 46406. https://doi.org/10.1002/app.48848.

[28] L. Luduena, D. Fasce, V.A. Alvarez, P.M. Stefani, Nanocellulose from rice husk following alkaline treatment to remove silica, BioResources 6 (2011) 440-1453.

[29] Y. Cao, S. Shiabata, I. Fukumoto, Mechanical properties of biodegradable composites reinforced with bagasse fibre before and after alkali treatments, Composites: Part A 37 (2006) 423-429. https://doi.org/10.1016/j.compositesa.2005.05.045.

[30] B.S. Ndazi, S. Karlsson, J.V. Tesha, C.W. Nyahumwa, Chemical and physical modifications of rice husks for use as composite panels, Composites Part A 38 (2007) 925935. DOI: 10.1016/j.compositesa.2006.07.004.

[31] H. Kargarzadeh, N. Johar, I. Ahmad, Starch biocomposite film reinforced by multiscale rice husk fiber, Compos. Sci. Technol. 151 (2017) 147-155.

DOI: 10.1016/j.compscitech.2017.08.018.

[32] A. Oushabi, S. Sair, F.O. Hassani, Y. Abboud, O. Tanane, A.E. Bouari, The effect of alkali treatment on mechanical, morphological and thermal properties of date palm fibers (DPFs): study of the interface of DPF-polyurethane composite, S. Afr. L. Chem. Eng. 23 (2017) 116-123. DOI : 10.1016/j.sajce.2017.04.005. 
[33] S. Wong, R. Shanks, A. Hodzic, Interfacial improvements in poly(3-hydroxybutyrate)flax fibre composites with hydrogen bonding additive, Compos. Sci. Technol. 64 (2004) 1321-1330. https://doi.org/10.1016/j.compscitech.2003.10.012.

[34] M.M. Abou-Mesalam, M.M. Sorption kinetics of copper, zinc, cadmium and nickel ions on synthesized-antimonate exchanger, Colloid Surfaces A 225 (2003) 85-94. https://doi.org/10.1016/S0927-7757(03)00191-2.

[35] R. Syafri, I. Ahmad, I. Abdullah, Effect of rice husk modification by LENR on the mechanical properties of NR/HDPE reinforced rice husk composite, Sains Malaysian 40 (2001) 749-756.

[36] F.S. Tong, S.C. Chin, M.T. Mustafa, H.R. Ong, M.M.R. Khan, J. Gimbun, S.I. Doh, Influence of alkaline treatment on physico-chemical properties of Malaysian bamboo fiber: a preliminary study, Malaysian J. Anal. Sci. 22 (2018) 143-150. DOI: 10.17576/mjas-20182201-18.

[37] Z. Emdadi, N. Asim, M.A. Yarmo, K. Sopian, Effect of chemical treatments on rice husk (RH) water absorption property, Int. J. Chem. Eng. 6 (2015) 273-276.

DOI: 10.7763/IJCEA.2015.V6.495.

[38] D.C. Marin, A. Vecchio, L.N. Luduena, D. Fasce, V.A. Alvarez, P.M. Stefani, Revalorization of rice husk waste as a source of cellulose and silica, Fiber. Polym. 16 (2015) 285-293. DOI: 10.1007/s12221-015-0285-5.

[39] J. Gassan, A.K. Bledzki, Alkali treatment of jute fibers. Relation between structure and mechanical properties, J. Appl. Polym. Sci. 71 (1999) 623-629. https://doi.org/10.1002/(SICI)1097-4628(19990124)71:4<623::AID-APP14>3.0.CO;2-K. 
[40] N. Shanmugasundaram, I. Rajendran, Characterization of raw and alkali-treated mulberry fibers as potential reinforcement in polymer composites, J. Reinf. Plast. Compos. 35 (2016) 601-614. https://doi.org/10.1177/0731684415625822.

[41] E.M. Ciannamea, P.M. Stefani, R.A. Ruseckaite, Medium-density particleboards from modified rice husks and soy bean protein concentrate-based adhesives, Bioresoour. Technol. 101 (2010) 818-825. https://doi.org/10.1016/j.biortech.2009.08.084.

[42] G.S. Gehlen, P.D. Neis, L.Y. de Barros, J.C. Poletto, M. Ebeling, N.F. Ferreira, S.C. Amico, C.C. Angrizani, Tribological behavior of glass/sisal fiber reinforced polyester composites, Polym. Compos. 41 (2020) 112-120. https://doi.org/10.1002/pc.25350.

[43] R.A. Martin, M.A. Martins, O.R.R.F. da Silva, L.H.C. Mattoso, Studies on the thermal properties of sisal fiber and its constituents, Thermochim. Acta. 506 (2010) 14-19. https://doi.org/10.1016/j.tca.2010.04.008.

[44] S.N. Monteiro, V. Calado, R.J.S. Rodriguez, F.M. Margem, Thermogravimetric stability of polymer composites reinforced with less common lignocellulosic fibers - an overview, J. Mater. Res. Technol. 1 (2012) 117-126.

[45] H.S. Kim, H.S. Yang, H.J. Kim, H.J, Park, Thermogravimetric analysis of rice husk flour filled thermoplastic polymer composites, J. Therm. Anal. Calorim. 76 (2004) 395-404. https://doi.org/10.1016/S2238-7854(12)70021-2.

[46] F. Wang, S. Zhou, M. Yang, Z. Chen, S. Ran, Thermo-mechanical performance of polylactide composites reinforced with alkali-treated bamboo fibers, Polymers 10 (2018) 401. DOI: $10.3390 /$ polym10040401. 
[47] V.A. Alvarez, A. Vazquez, Thermal degradation of cellulose derivatives starch blends and sisal fibres biocomposites, Polym. Degrad. Stabil. 84 (2004) 13-21.

https://doi.org/10.1016/j.polymdegradstab.2003.09.003.

[48] B.S. Ndazi, C.W. Nyahumwa, J. Tesha, Chemical and thermal stability of rice husks against alkali treatment, BioResources 3 (2008) 1267-1277.

[49] R.A. Ruseckaite, E.M. Ciannamea, P. Leiva, P.M. Stefan, Particleboards based on rice husk. In: G. E. Zaikov, \& A. Jimenez (Eds.), Polymer and Biopolymer analysis and characterization, Nova Science Publishing Inc., New York, 2007, pp. 1-12.

[50] L.K. Shrestha, M. Thapa, R.G. Shrestha, S. Maji, R.R. Pradhananga, K. Ariga, Rice husk-derived high surface area nanoporous carbon materials with excellent iodine and methylene blue adsorption properties, C-Journal of Carbon Research, 5 (2019) doi:10.3390.c5010010.

[51] Y. Hsieh, Y. Du, F. Jin, Z. Zhou, H. Ecomoto, Alkaline pre-treatment of rice hulls for hydrothermal production of acetic acid, Chem. Eng. Res. Des. 87 (2009) 13-18. https://doi.org/10.1016/j.cherd.2008.07.001.

[52] P.A. Sreekumar, M.A. Al-Harthi, S.K. De, Effect of glycerol on thermal and mechanical properties of polyvinyl alcohol/starch blends, J. Appl. Polym. Sci. 123 (2012) 135-142. https://doi.org/10.1002/app.34465.

[53] Y. Chen, X. Cao, P.R. Chang, M.A. Huneault, Comparative study on the films of poly(vinyl alcohol)/pea starch nanocrystals and poly(vinyl alcohol)/native pea starch, Carbohydr. Polym. 73 (2008) 8-17. https://doi.org/10.1016/j.carbpol.2007.10.015. 
[54] K. Kačuráková, M. Mathlouthi, FTIR and laser-Raman spectra of oligosaccharides in water: characterization of the glycosidic bond, Carbohydr. Res. 284 (1996) 145-157.

DOI: 10.1016/0008-6215(95)00412-2.

[55] H.L. Boudjema, H. Bendaikha, Composite materials derived from biodegradable starch polymer and Atriplex halimus fibers, e-Polymers 15 (2015) 419-426. https://doi.org/10.1515/epoly-2015-0118.

[56] S.M. Mbeche, T. Omara, 2020. Effects of alkali treatment on the mechanical and thermal properties of sisal/cattail polyester commingled composites, PeerJ Material Science Chemistry 2:e5. http://doi.org/10.7717/peerj-matsci.5.

[57] M.Y. Tan, H.T.N. Kuan, M.C. Lee, Characterization of alkaline treatment and fiber content on the physical, thermal, and mechanical properties of ground coffee waste/oxobiodegradable HDPE biocomposites, International Journal of Polymer Science Volume 2017, https://doi.org/10.1155/2017/6258151.

[58] D.O. Bichang'a, P.M. Wambua, E.O. Nganyi, The effect of alkali treatment on the mechanical properties of sisal fiber reinforced epoxy composites, Am. J. Eng. Res. 4 (2017) 31-39.

[59] P. Gañan, S. Garbizu, R. Llano-Ponte, I. Mondragon, Surface modification of sisal fibers: effects on the mechanical and thermal properties of their epoxy, Polym. Compos. 26 (2005) 121-127. DOI: 10.1002/pc.20083.

[60] S. Rizal, Ikramullah, D.A. Gopakumar, S. Thalib, S. Huzni, H.P.S. Abdul Khalil. Interfacial compatibility evaluation on the fiber treatment in the typha fiber reinforced epoxy composites and their effect on the chemical and mechanical properties, Polymers 10 (2018)1316. DOI 10.3390/polym10121316.

[61] F.L. Matthews, R.D. Rawlings, Composite materials: engineering and science. 1st edition. Cambridge: Woodhead Publishing, 1999, p. 480. 
[62] J. Gassan, A.K. Bledzki, Alkali treatment of jute fibers: relationship between structure and mechanical properties, J. Appl. Polym. Sci. 71 (1999) 623-629.

https://doi.org/10.1002/(SICI)1097-4628(19990124)71:4<623::AID-APP14>3.0.CO;2-K.

[63] K. Mylsamy, I. Rajendran, The mechanical properties, deformation and

thermomechanical properties of alkali treated and untreated Agave continuous fibre

reinforced epoxy composites, Mater. Des. 32 (2011) 3076-3084.

https://doi.org/10.1016/j.matdes.2010.12.051.

[64] M.S. Sreekala, M.G. Kumaran, S. Thomas, Stress relaxation behaviour in oil palm fibres, Mater. Lett. 50 (2001) 263-273. https://doi.org/10.1016/S0266-3538(00)00214-1.

[65] K.B. Adhikary, S. Pang, M.P. Staiger, Long-term moisture absorption and thickness swelling behavior of recycled thermoplastics reinforced with pinus radiate sawdust, Chem. Eng. J. 142 (2008) 190-198. DOI: 10.1016/j.cej.2007.11.024.

[66] S.A. Weerawarna (2009). Method for making biodegradable superabsorbent particles. U.S. Patent 2009/0324731 A1, filed June 30, 2008, and issued December 31, 2009. [67] J.D. Stahl, M.D. Cameron, J. Haselbach, S.D. Aust, Biodegredation of superabsorbent polymers in soil, Environ. Sci. Pollut. Res. Int. 7 (2000) 83-88.

DOI: 10.1065/espr199912.014. 